\title{
EFEITO DE DIFERENTES LÂMINAS DE IRRIGAÇÃO NA CULTURA DO MAMÃO
}

\author{
FRANCISCO S. S. DOS SANTOS ${ }^{1}$, THALES V. A. VIANA ${ }^{2}$, BENITO M. DE AZEVEDO ${ }^{2}$, \\ CARLOS W. OLIVEIRA ${ }^{3}$, ANTONIO E. C. SOUSA ${ }^{4}$
}

RESUMO: O objetivo deste trabalho foi estudar o efeito de diferentes lâminas de irrigação na cultura do mamão (Carica papaya L.), grupo Formosa, variedade 'Tainung $\mathrm{N}^{\mathrm{o}}$ 1', nas condições edafoclimáticas do Distrito de Irrigação Jaguaribe Apodi (DIJA), Limoeiro do Norte, Ceará. Para isso, foram aplicados níveis de irrigação correspondentes a 50; 75; 100; 125 e $150 \%$ da evaporação do Tanque Classe "A" (ECA). Utilizou-se do delineamento experimental de blocos casualizados, com três repetições e cinco tratamentos. As variáveis analisadas foram massa média do fruto, produtividade e teor de sólidos solúveis totais. Os resultados obtidos demonstraram que a utilização de maiores lâminas de irrigação aumenta a produtividade, entretanto não altera a massa média do fruto e o teor de sólidos solúveis totais.

PALAVRAS-CHAVE: Carica papaya L., tanque Classe “A”, produtividade, manejo de irrigação.

\section{EFFECT OF DIFFERENT DEPTH IRRIGATION IN PAPAYA CROP}

\begin{abstract}
The objective of this work was to study the effect of the different irrigation levels at the Carica papaya L. crop, Formosa group, variety Tainung $\mathrm{N}^{\circ} 1$, under the edapho-climatic conditions at the Jaguaribe Apodi Irrigation District (DIJA), Limoeiro do Norte, Ceará. It was applied irrigation levels corresponding to $50 ; 75 ; 100 ; 125$ and $150 \%$ of the Class A Pan evaporation (ECA). The experimental delineation used was randomized blocks design with three repetitions and five treatments. The analyzed attributes were: average weight of the fruit, productivity and levels of total soluble solids in the fruit. The results demonstrated that the use of bigger irrigation depths increases the productivity. However, it does not modify the average weight of the fruit and the levels of total soluble solids.
\end{abstract}

KEYWORDS: Carica papaya L., pan class “A”, productivity, irrigation management.

\section{INTRODUÇÃO}

Nos últimos dez anos, o mamão foi a cultura tropical que mais se desenvolveu em termos de aumento de produção. Segundo dados da FAO, no período de 1990/1999, houve incremento de $41 \%$, passando de 3,5 para 5 milhões de toneladas. Analisando o mesmo período, no Brasil, o aumento foi de $154 \%$ (BRASIL, 2000). O Estado do Ceará, por sua vez, teve sua área colhida acrescida em mais de 570\% no período de 1990/2002 (IBGE, 2006).

No Ceará, MATIAS \& SILVA (2001), analisando o panorama da cultura de 1990 a 1999, verificaram que a área colhida e a produção apresentaram tendência crescente ao longo do período, com taxas anuais médias de crescimento de 15,82 e 15,2\%, respectivamente. No que diz respeito ao rendimento médio, segundo os mesmo autores, observou-se que, nos últimos 10 anos, ocorreram aumentos relativamente pequenos, numa taxa de apenas $2,21 \%$ ao ano; portanto, aumento de rendimento que contrasta com o aumento na área e na produção.

A importância da água para o mamoeiro relaciona-se tanto à falta quanto ao excesso. A restrição hídrica, além de reduzir o crescimento da planta, favorece a produção de flores masculinas

\footnotetext{
${ }^{1}$ Tecnólogo em recursos hídricos/irrigação, Professor da Faculdade de Tecnologia - CENTEC, Limoeiro do Norte - CE, Fone: (0XX88) 9964.2232, sildemberry@ hotmail.com

${ }^{2}$ Eng $^{\mathrm{o}}$ Agrônomo, Prof. Doutor, Departamento de Engenharia Agrícola, UFC, Fortaleza - CE.

${ }^{3}$ Eng $^{\mathrm{O}}$ Agrônomo, Prof. Doutor, Departamento de Engenharia Agrícola, UFC, Juazeiro do Norte - CE.

${ }^{4}$ Tecnólogo em recursos hídricos/irrigação, Doutorando em Engenharia Agrícola, UFCG, Campina Grande - PB.

Recebido pelo Conselho Editorial em: 9-11-2007
}

Aprovado pelo Conselho Editorial em: 21-1-2009

Eng. Agríc., Jaboticabal, v.28,n.4, p.673-680, out./dez. 2008 
e estéreis, reduzindo a produção de frutos. Por outro lado, o excesso de água na região em torno da raiz da planta diminui a aeração e afeta a absorção de nutrientes, aumenta o aparecimento de doenças, além de possibilitar a lixiviação dos nutrientes (MARIN et al., 1995).

Dentro desse contexto, a adoção da tecnologia de irrigação para a cultura do mamoeiro, para o real sucesso do empreendimento, deve ser respaldada por recomendações adequadas de manejo de água, que permitam o seu uso racional (COELHO et al., 2003; SANCHES \& DANTAS, 1999).

Entretanto, na região em estudo, é comum os produtores estabelecerem tempo de irrigação arbitrário, baseado na tradição local ou em recomendações de profissionais.

Muitas pesquisas têm sido desenvolvidas para a adequação do manejo da irrigação com base no tanque Classe "A". CHAVES (2004) afirma que esse fato é de suma importância. Segundo o autor, o manejo de irrigação realizado com a utilização desse equipamento, simples e barato, permite ao produtor definir o manejo da irrigação sem a necessidade de cálculos complexos.

Vários trabalhos foram desenvolvidos em outros Estados brasileiros com o objetivo de estudar o manejo da irrigação do mamoeiro. SILVA et al. (2001) avaliaram os efeitos da interação entre lâmina de água aplicada e frequências de aplicação sobre a produção comercial e outros componentes produtivos do mamoeiro Sunrise Solo Line 72/12, em Sooretama - ES. Ao final, verificaram que a produtividade, a massa média dos frutos e o número de frutos por planta cresceram linearmente com a lâmina aplicada, correspondente às reposições de $40 ; 60 ; 80 ; 100$ e $120 \%$ da evapotranspiração obtida a partir do tanque Classe "A".

COELHO et al. (2003) verificaram o mesmo efeito na produtividade do mamoeiro, tendo obtido o valor máximo com a utilização de lâmina de irrigação equivalente a $120 \%$ da evapotranspiração obtida pelo tanque Classe "A", na região de Linhares - ES. Aplicando lâminas de 0 até $240 \%$ da evapotranspiração de referência, baseada no tanque Classe "A", ALMEIDA et al. (2003) verificaram aumento de quase $420 \%$ na produtividade do mamão Improved Sunrise Solo 72/12, em Campos dos Goytacazes - RJ.

GARCIA (2004), em Limoeiro do Norte - CE, constatou que a água teve efeito altamente significativo sobre a massa média de frutos por planta, o número de frutos por planta, a massa média de frutos e a produtividade do mamão Formosa Híbrido "Know you Seed", irrigado por microaspersão.

As condições edafoclimáticas do Ceará favorecem o crescimento da cultura do mamão. Entretanto, a carência de informações sobre o mamoeiro irrigado, variedade "Tainung $\mathrm{N}^{\mathrm{o}} 1$ ", nas condições edafoclimáticas do Estado, evidencia a necessidade de intensificação das pesquisas sobre essa cultura. Além disso, estudos que levem em conta a resposta da produção da cultura em relação a diferentes lâminas de irrigação são imprescindíveis à viabilidade e à difusão da exploração da cultura na região.

Nesse sentido, foi realizado este trabalho com o objetivo de estudar o efeito de diferentes lâminas de irrigação sobre os aspectos produtivos do mamão e as possíveis influências no teor de sólidos solúveis totais, nas condições edafoclimáticas de Limoeiro do Norte - CE.

\section{MATERIAL E MÉTODOS}

O experimento foi desenvolvido no Distrito de Irrigação Jaguaribe-Apodi (DIJA), na área experimental da agroempresa Frutacor, localizada na Chapada do Apodi, Limoeiro do Norte, Ceará (0506'S; 38 00'W; $151 \mathrm{~m})$. De acordo com a classificação de Köeppen, o clima é do tipo BSw'h'. A região apresenta os seguintes valores médios anuais: precipitação de $772 \mathrm{~mm}$, irregular; temperatura de $28,5^{\circ} \mathrm{C}$; umidade relativa de $62 \%$ e insolação de 3.030 horas (DNOCS, 2006).

O solo da área experimental apresenta textura franco-argilo-arenosa, relevo uniforme, plano e declividade muito suave (BASTOS, 2004) e pertence à ordem dos Cambissolos, subordem Cambissolo Háplico, derivado de rochas calcárias, formação Jandaíra (EMBRAPA, 1999). 
O experimento iniciou-se com o preparo do solo, constando sucessivamente de subsolagem, gradagem cruzada, sulcamento e formação dos camalhões. Em seguida, foi feita a marcação das covas, seguindo o espaçamento $4 \mathrm{~m}$ entre fileiras duplas, $2 \mathrm{~m}$ entre fileiras simples e $2,4 \mathrm{~m}$ entre plantas.

Posteriormente, instalou-se o sistema de irrigação e realizou-se a adubação de fundação, usando-se $12 \mathrm{~L}$ de esterco ovino e $200 \mathrm{~g}$ de fosfato monoamônio (MAP) por cova. As adubações foram realizadas via fertirrigação mediante recomendação feita a partir de análise de solo, sendo as fertirrigações feitas duas vezes por semana. Em complemento, aplicaram-se também adubos foliares para suprir a necessidade dos demais elementos (ferro, zinco, cobre, manganês, molibdênio e boro).

Sempre que necessário, aplicaram-se também defensivos agrícolas de caráter preventivo e curativo. As ervas daninhas foram controladas química e mecanicamente, com o uso de herbicidas e de capinas manual e mecanizada.

As sementes foram semeadas em bandejas, em células, e o transplantio das mudas realizado quando as mesmas tinham em torno de 27 dias. Optou-se por plantar duas mudas por cova a fim de obter maior número de plantas hermafroditas na área.

A seleção das plantas hermafroditas (sexagem) iniciou-se 63 dias após o transplantio (DAT), quando a maior parte das plantas apresentava flores definidas.

Devido à alta incidência de brotos laterais indesejáveis, iniciou-se a desbrota em torno dos 70 DAT. O raleio de flores foi iniciado aos 94 DAT, deixando-se apenas uma flor por axila.

O experimento foi irrigado utilizando um sistema de irrigação por gotejamento, composto por fitas gotejadoras com diâmetro nominal de $16 \mathrm{~mm}$, emissores espaçados de $0,80 \mathrm{~m}$, com vazão de $4 \mathrm{~L} \mathrm{~h}^{-1}$ e pressão de serviço de 10 mca (Figura 1).

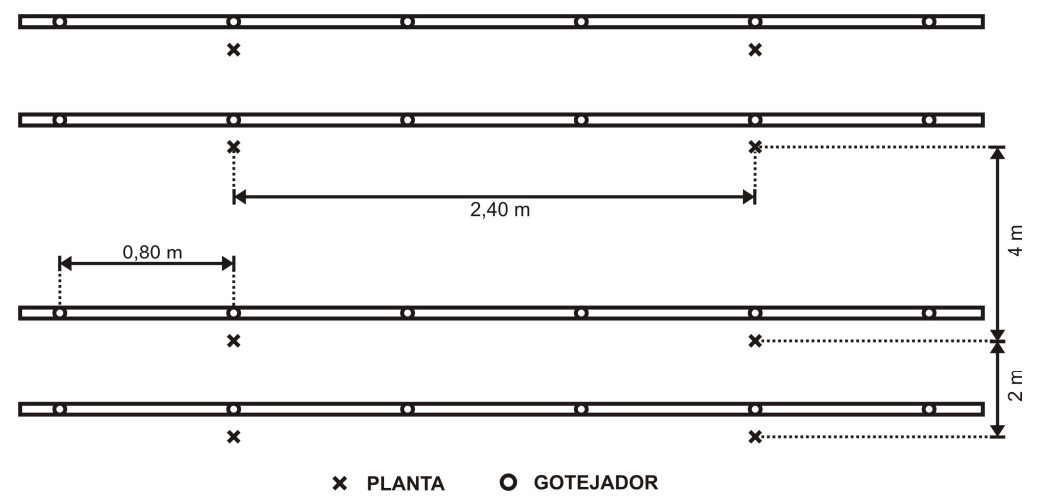

FIGURA 1. Esquema da distribuição do sistema no campo, mostrando o espaçamento entre plantas e a distribuição dos gotejadores. Layout of plants spacing and drip distribution.

A eficiência de aplicação foi determinada utilizando-se das eqs.(1) e (2), conforme metodologia de MERRIAN \& KELLER (1978):

$$
\mathrm{CU}=\frac{\mathrm{q}_{\mathrm{n}}}{\mathrm{q}_{\mathrm{a}}} 100
$$

em que,

CU - coeficiente de uniformidade, $\%$;

$\mathrm{q}_{\mathrm{n}}$ - vazão média das $25 \%$ menores vazões dos emissores, $\mathrm{L} \mathrm{h}^{-1}, \mathrm{e}$

$\mathrm{q}_{\mathrm{a}}$ - média das vazões de todos os emissores, $\mathrm{L} \mathrm{h}^{-1}$.

$$
\mathrm{Ea}=\mathrm{Ks} \mathrm{CU}
$$

em que,

Ea - eficiência de aplicação, e

Ks - coeficiente de transmissividade. 
O coeficiente de transmissividade, função do clima, da profundidade do sistema radicular e da textura do solo, foi estabelecido como 1,0.

O tempo de irrigação (T) foi calculado pela eq.(3):

$$
\mathrm{T}=\frac{\% \mathrm{ECA} \mathrm{A}_{\mathrm{P}} \mathrm{Fc}}{\mathrm{Ea} \mathrm{q}_{\mathrm{a}}}
$$

em que,

T - tempo de irrigação, h;

\%ECA - evaporação do tanque Classe "A", lâmina de irrigação variável com os tratamentos, $\mathrm{mm}$;

$A_{P}$ - área ocupada pela planta, $\mathrm{m}^{2}$;

Fc - fator de cobertura, decimal;

Ea - eficiência de aplicação, e

$\mathrm{q}_{\mathrm{a}}$ - média das vazões de todos os emissores em $\mathrm{L} \mathrm{h}^{-1}$.

O fator de cobertura representa a relação entre a área molhada e a área ocupada pela cultura, que deve ser de, no mínimo, 30\% (0,3) para frutíferas. Foi utilizado o valor 0,4 para o cálculo do tempo de irrigação, durante todo o ciclo estudado.

O delineamento experimental foi o de blocos completos casualizados com três repetições, considerando 12 plantas úteis por tratamento. Foram empregados cinco tratamentos, que se distinguiram pela lâmina de água aplicada: 50; 75; 100; 125 e $150 \%$ da evaporação do tanque Classe "A" (ECA). As lâminas aplicadas nos diferentes tratamentos foram controladas por meio de registro de polietileno instalado no início de cada linha lateral.

A colheita iniciou-se aos 225 DAT, sendo realizada em intervalos de dez dias, aproximadamente, até os 282 DAT. Em cada colheita, selecionou-se um fruto representativo por planta para medir o teor de sólidos solúveis (em ${ }^{\circ}$ Brix), sete dias após. A seleção do fruto seguia critérios de sanidade, além de formato e massa medianos, excluindo-se aqueles com características extremas.

No final do ensaio em campo, aos 282 DAT, foram analisadas as seguintes variáveis: massa média (g) e teor de sólidos solúveis dos frutos $\left({ }^{\circ} \mathrm{Brix}\right)$, bem como a produtividade $\left(\mathrm{Mg} \mathrm{ha}^{-1}\right)$.

De posse dos dados, foi realizada a análise de variância para cada variável. Para as variáveis que mostraram efeito significativo dos tratamentos pelo teste F, procedeu-se à análise de regressão, com o propósito de ajustar modelo matemático que descrevesse esse efeito. Para esse propósito, foi utilizado o software "SAEG/UFV 9.0", sendo selecionado o modelo que apresentou melhores níveis de significância e coeficiente de determinação $\left(\mathrm{R}^{2}\right)$.

\section{RESULTADOS E DISCUSSÃO}

Na Tabela 1, constam os resultados da análise de variância das características analisadas para os diversos tratamentos. Ressalta-se que os tratamentos $1 ; 2 ; 3 ; 4$ e 5 se referem à aplicação das lâminas de irrigação correspondentes a 50; 75; 100; 125 e 150\% da ECA.

Não houve significância para o teor de sólidos solúveis totais (Tabela 1), corroborando SILVA et al. (2001), que também não observaram efeitos da lâmina de irrigação no teor de SST no mamão. Resultados similares foram obtidos por NEGREIROS et al. (2005), que não verificaram influência significativa das lâminas de irrigação no teor de sólidos solúveis do melão.

Por outro lado, resultados divergentes foram encontrados por outros ensaios. PEW \& GARNWER (1983) concluíram que a irrigação excessiva pode prejudicar a qualidade final do fruto de melão. Tal fato foi confirmado por PÉREZ \& CIGALES (2001), citados por VÁSQUEZ et al. (2005), ao verificarem que a tendência foi diminuir de 10,0 para 9,2 o teor de SST nos frutos de melão, ao se aumentar o conteúdo de água no solo. 
TABELA 1. Valores médios de massa do fruto (MMF), produtividade (PROD) e sólidos solúveis totais (SST) obtidos para as diferentes lâminas de irrigação e teste F da análise de variância. Variance analysis of mean weight fruit (MWF), productivity (PROD), total soluble solids (TSS) from different water irrigation depths applied to Formosa's papaya.

\begin{tabular}{cccc}
\hline Tratamento & MMF $(\mathrm{g})$ & PROD $\left(\mathrm{Mg} \mathrm{ha}^{-1}\right)$ & SST $\left({ }^{\mathbf{o}}\right.$ Brix $)$ \\
\hline 1 & $1.881,18$ & 21,324 & 11,99 \\
2 & $1.916,82$ & 32,153 & 12,65 \\
3 & $1.816,93$ & 27,498 & 12,21 \\
4 & $2.454,37$ & 39,306 & 11,70 \\
5 & $2.116,76$ & 42,722 & 12,32 \\
\hline Média & $2.037,21$ & 32,601 & 12,17 \\
C.V. $(\%)$ & 71,38 & 19,78 & 8,57 \\
F & $2,49^{*}$ & $4,32^{*}$ & $1,41^{\mathrm{ns}}$ \\
\hline
\end{tabular}

T1 - 0,5ECA* / T2 - 0,75ECA / T3 - 1,0ECA / T4 - 1,25ECA / T5 - 1,5ECA

*ECA - evaporação do tanque Classe "A"

Houve influência do incremento das lâminas de irrigação sobre a massa média dos frutos (Tabela 1). O tratamento com $125 \%$ de ECA proporcionou maior massa média dos frutos. Entretanto, não houve diferença significativa desse com os tratamentos 1; 2 e 5 (50; 75 e 150\% de ECA, respectivamente). O menor valor de massa média foi obtido com a aplicação de $100 \%$ da ECA, diferindo significativamente apenas do quarto tratamento (125\% da ECA).

A partir da análise de regressão, constatou-se que não houve ajuste adequado para a massa média dos frutos, embora a análise de variância tenha apontado influência dos tratamentos sobre a variável. GARCIA (2004) obteve resultados diferentes, verificando que o modelo de regressão linear expressou a variação da massa do fruto em função do incremento da lâmina de irrigação no mamoeiro. Da mesma forma, SILVA et al. (2001) constataram efeito linear das lâminas de irrigação sobre a cultura do mamão, utilizando turnos de rega de 2; 3 e 5 dias. A produtividade foi influenciada pelo aumento da lâmina de irrigação (Tabela 1). O maior rendimento foi obtido com a aplicação da maior lâmina de irrigação ( $150 \%$ da ECA), apesar de ser estatisticamente igual aos rendimentos dos tratamentos intermediários (75; 100 e $125 \%$ da ECA). Em contrapartida, o rendimento no tratamento com menor lâmina foi inferior aos demais, porém não diferindo dos tratamentos $2 ; 3$ e 4.

A análise de regressão apontou tendência linear positiva para a produtividade $\left(\mathrm{Mg} \mathrm{ha}^{-1}\right) \mathrm{em}$ função das lâminas de irrigação (Figura 2). Segundo o modelo proposto, 82,94\% da variação da produtividade do mamão pode ser explicada pela equação de primeiro grau $\hat{Y}=199,8 * X+12621$.

$\mathrm{O}$ incremento observado na produtividade entre a menor e a maior lâmina de irrigação foi superior a $100 \%$, com amplitude de mais de $21 \mathrm{Mg} \mathrm{ha}^{-1}$. Vale ressaltar que foram realizadas, no total, cinco colheitas durante cerca de dois meses, promovendo, desse modo, pequenas produtividades.

Os resultados obtidos confirmam SANCHES \& DANTAS (1999), que afirmaram que a irrigação acarreta aumento na produtividade do mamoeiro, favorecendo os processos de crescimento, floração e frutificação da planta. Desse modo, verifica-se a essencialidade da água na produção do mamoeiro, dada a correlação observada entre a aplicação de lâminas de irrigação e a capacidade produtiva da planta. Resultados similares foram encontrados por SILVA et al. (2001), COELHO et al. (2003), GARCIA (2004) e CHAVES (2004). 


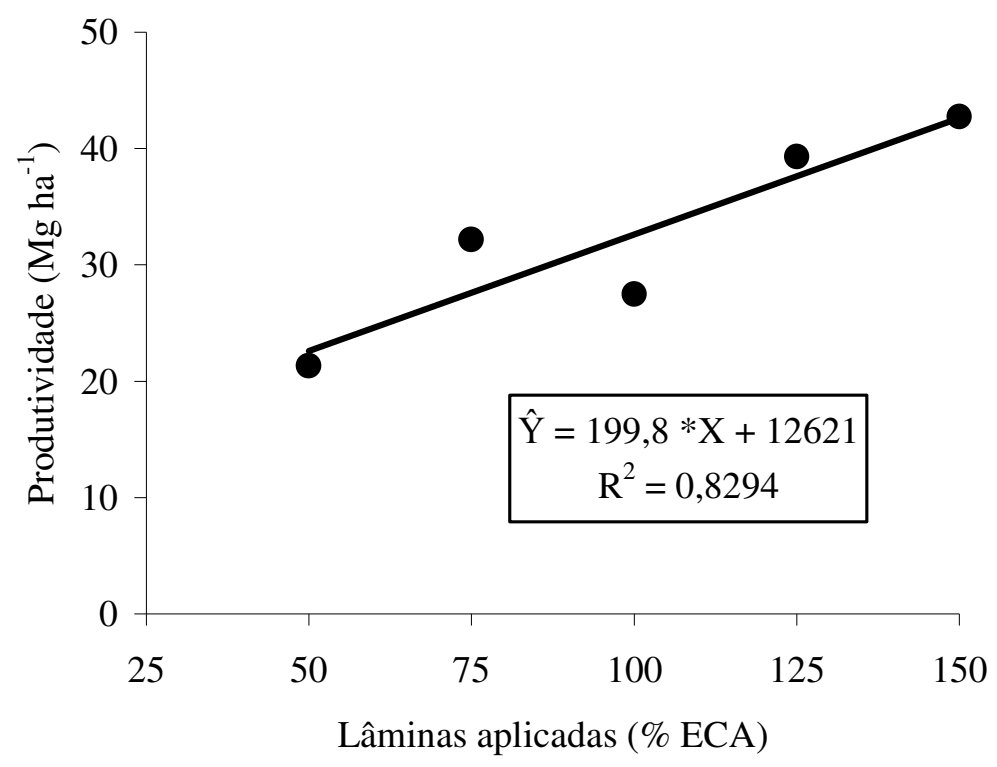

FIGURA 2. Produtividade do mamoeiro Tainung $\mathrm{N}^{\circ} 1$ em função das lâminas crescentes de irrigação. Papaya productivity (Tainung $\mathbf{N}^{\circ}$ 1) as a function of increasing irrigation depths.

Aplicando lâminas superiores às estudadas neste ensaio, COELHO et al. (2003) verificaram declínio na curva de produtividade do mamoeiro com máximo para $290 \%$ de ETo, em condições semiáridas. ALMEIDA et al. (2003) obtiveram relação semelhante à identificada no presente trabalho, com mamão Improved Sunrise Solo 72/12, aplicando lâminas de irrigação de 0 a $240 \%$ da ETo, em Campos dos Goytacazes, Rio de Janeiro.

Por outro lado, outros estudos revelam divergências em relação aos resultados discutidos, tanto para o mamoeiro, como para outras culturas. COELHO et al. (2003) declaram que a relação entre a produtividade do mamoeiro e a quantidade de água necessária tem-se mostrado quadrática, com máximo para $150 \%$ da ETo nas condições dos Tabuleiros Costeiros do Recôncavo Baiano. Do mesmo modo, BASTOS (2004) identificou relação descrita por modelo quadrático negativo na produtividade da melancia em função dos níveis de irrigação de 25; 50; 75; 100 e 125\% da evaporação do Tanque Classe "A", no Distrito de Irrigação Jaguaribe-Apodi, em Limoeiro do Norte - CE.

Com a aplicação das lâminas de 50 a 150\% ECA, foi verificada tendência linear positiva da curva de resposta da produtividade. O emprego de lâminas superiores poderia, possivelmente, promover a alteração da inclinação do gráfico, gerando até mesmo valores negativos, uma vez que, segundo MARIN et al. (1995), o excesso de água na região em torno da raiz da planta diminui a aeração e afeta a absorção de nutrientes, aumenta o aparecimento de doenças, além de possibilitar a lixiviação dos nutrientes. Diante disso, torna-se importante a realização de novos ensaios, aplicando-se lâminas superiores a $150 \%$ da evaporação do Tanque Classe "A", buscando avaliar a hipótese do decréscimo dos valores medidos, decorrente do aumento da quantidade de água aplicada.

\section{CONCLUSÕES}

Os resultados obtidos demonstraram que a utilização das maiores lâminas de irrigação não promoveu alteração do teor de sólidos solúveis totais. Entretanto, a produtividade da cultura cresceu linearmente com a elevação dos valores de lâmina aplicada. 


\section{AGRADECIMENTOS}

À Empresa Frutacor, pelo apoio técnico-financeiro; ao CNPq, pela cessão de bolsa de estudos, e à Faculdade de Tecnologia CENTEC-Limoeiro do Norte, pelo suporte nos equipamentos.

\section{REFERÊNCIAS}

ALMEIDA, F. T. de; BERNARDO, S.; SOUSA, E. F. de; MARIN, S. L. D.; GRIPPA, S. Growth and yield of papaya under irrigation. Scientia Agricola, Piracicaba, v.60, n.3, p.419-24, 2003.

BASTOS, F. G. C. Efeitos de níveis de irrigação, de doses de nitrogênio e de espaçamentos na cultura da melancia. 2004. 62 f. Dissertação (Mestrado em Irrigação e Drenagem) - Universidade Federal do Ceará, Fortaleza, 2004.

BRASIL. Ministério da Integração Nacional. FrutiSéries 7 - Mamão. Brasília, 2000. 8 p.

CHAVES, S.W.P. Coeficiente de cultivo, necessidade hídrica e adubação nitrogenada na cultura da pimenta. 2004. 59 f. Dissertação (Mestrado em Irrigação e Drenagem) - Universidade Federal do Ceará, Fortaleza, 2004.

COELHO, E.F.; SILVA, J.G.F. da; ALVES, A.A.C.; CRUZ, J.L. Irrigação do mamoeiro. Cruz das Almas: Embrapa Mandioca e Fruticultura, 2003. 8 p. (Circular Técnica, 54).

DNOCS. DEPARTAMENTO NACIONAL DE OBRAS CONTRA AS SECAS. Perímetro irrigado Jaguaribe-Apodi. 2006. Disponível em: < http://201.30.148.11/ apoena/php/projetos/projetos.php > Acesso em: 12 jan. 2006.

EMBRAPA. EMPRESA BRASILEIRA DE PESQUISA AGROPECUÁRIA. Sistema Brasileiro de Classificação de Solos. Brasília, 1999. 412 p.

GARCIA, F.C. de H. Efeitos de níveis de irrigação na cultura do mamoeiro na Chapada do Apodi CE. 2004. 31 f. Dissertação (Mestrado em Irrigação e Drenagem) - Universidade Federal do Ceará, Fortaleza, 2004.

IBGE. INSTITUTO BRASILEIRO DE GEOGRAFIA E ESTATÍSTICA. Disponível em: $<\mathrm{ftp} / / / \mathrm{ftp}$. ibge.gov.br/Producao_Agricola/Producao_Agricola_Municipal_\%5Banual\%5D/>. Acesso em: $1^{\underline{0}}$ fev. 2006.

MARIN, S.L.D.; GOMES, J.A.; SALGADO, J.S.; MARTINS, D.S.; FULLIN, E.A. Recomendações para a cultura do mamoeiro dos grupos Solo e Formosa no Estado do Espírito Santo. 4.ed. Vitória: EMCAPA, 1995. 57 p. (Circular Técnica, 3).

MATIAS, G.D.V.; SILVA, L.M.R. Panorama da cultura do mamão no Estado do Ceará. In: SIMPÓSIO DE INOVAÇÕES TECNOLÓGICAS E GERENCIAIS, 1., 2001, Fortaleza. Anais... Fortaleza: Embrapa Agroindústria Tropical/SINDIFRUTA, 2001. 191 p.

MERRIAN, J.L.; KELLER, J. Farm irrigation system evaluation: a guide for management. Logan: Utah State University, 1978. 271 p.

NEGREIROS, M.Z.; COSTA, F.A.; MEDEIROS, J.F.; LEITÃO, V.B.R.M.M.; BEZERRA NETO, F.; ESPÍNOLA SOBRINHO, J. Rendimento e qualidade do melão sob lâminas de irrigação e cobertura do solo com filmes de polietileno de diferentes cores. Horticultura Brasileira, Brasília, v.23, n.3, p.773-9, 2005.

PEW, W.D.; GARNWER B.R. Effects of irrigation practices on vine growth, yield, and quality of muskmelon. Journal American Society Horticultural Science, Alexandria, v.108, n.1, p.134-137, 1983.

SANCHES, N.F.; DANTAS, J.L.L. O cultivo do mamão. Cruz das Almas: Embrapa Mandioca e Fruticultura, 1999. 105 p. (Circular Técnica, 34). 
SILVA, J.G.F. da; FERREIRA, P. A.; COSTA, L.C.; MELENDES, R.R.V.; CECOM, P.R. Efeitos de diferentes lâminas e frequências de irrigação sobre a produtividade do mamoeiro (Carica papaya L.). Revista Brasileira de Fruticultura, Jaboticabal, v.23, n.3, p.597-601, 2001.

VÁSQUEZ, M.A.N.; FOLEGATTI, M.V.; DIAS, N.S.; SOUSA, V.F. Qualidade pós-colheita de frutos de meloeiro fertirrigado com diferentes doses de potássio e lâminas de irrigação. Revista Brasileira de Engenharia Agrícola e Ambiental, Campina Grande, v.9, n.2, p.199-204, 2005. 